PREPARED FOR THE U.S. DEPARTMENT OF ENERGY, UNDER CONTRACT DE-AC02-76CH03073

PPPL-3996

PPPL-3996

UC-70

Real-time Equilibrium Reconstruction and Isoflux Control

of Plasma Shape and Position

in the National Spherical Torus Experiment (NSTX)

by

D. Mueller, D.A. Gates, J.E. Menard, J.R. Ferron, and S.A. Sabbagh

August 2004

NM|

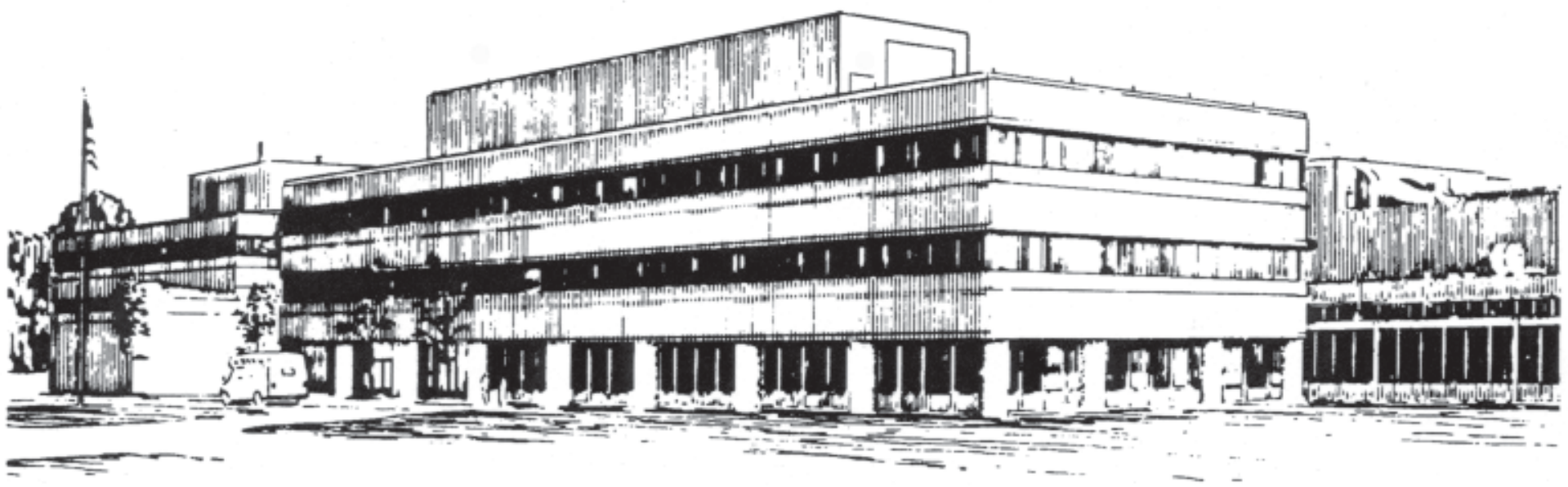

PRINCETON PLASMA PHYSICS LABORATORY PRINCETON UNIVERSITY, PRINCETON, NEW JERSEY 


\section{PPPL Reports Disclaimer}

This report was prepared as an account of work sponsored by an agency of the United States Government. Neither the United States Government nor any agency thereof, nor any of their employees, makes any warranty, express or implied, or assumes any legal liability or responsibility for the accuracy, completeness, or usefulness of any information, apparatus, product, or process disclosed, or represents that its use would not infringe privately owned rights. Reference herein to any specific commercial product, process, or service by trade name, trademark, manufacturer, or otherwise, does not necessarily constitute or imply its endorsement, recommendation, or favoring by the United States Government or any agency thereof. The views and opinions of authors expressed herein do not necessarily state or reflect those of the United States Government or any agency thereof.

\section{Availability}

This report is posted on the U.S. Department of Energy's Princeton Plasma Physics Laboratory Publications and Reports web site in Fiscal Year 2004. The home page for PPPL Reports and Publications is: http://www.pppl.gov/pub_report/

DOE and DOE Contractors can obtain copies of this report from:

U.S. Department of Energy

Office of Scientific and Technical Information

DOE Technical Information Services (DTIS)

P.O. Box 62

Oak Ridge, TN 37831

Telephone: (865) 576-8401

Fax: (865) 576-5728

Email: reports@adonis.osti.gov

This report is available to the general public from:

National Technical Information Service

U.S. Department of Commerce

5285 Port Royal Road

Springfield, VA 22161

Telephone: $1-800-553-6847$ or

(703) $605-6000$

Fax: (703) 321-8547

Internet: http://www.ntis.gov/ordering.htm 


\title{
Real-time equilibrium reconstruction and isoflux control of plasma shape and position in the National Spherical Torus Experiment (NSTX)*
}

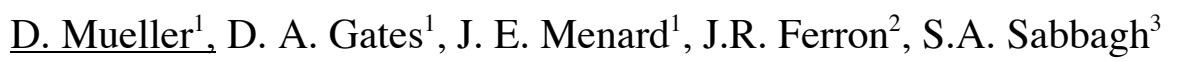 \\ 1. Princeton Plasma Physics Laboratory, P. O. Box 451, Princeton, NJ 08543, U.S.A. \\ 2. General Atomics, General Atomics Ct., San Diego, CA 92186, U.S.A. \\ 3. Columbia University, New York, NY 10027, U.S.A.
}

\section{Introduction}

The National Spherical Torus Experiment (NSTX) is a proof-of-principle experiment designed to study the physics of the spherical torus (ST), i.e. low aspect-ratio toroidal, plasmas. NSTX has produced plasmas with $\mathrm{R} / \mathrm{a} \sim 0.85 \mathrm{~m} / 0.68 \mathrm{~m}, \mathrm{~A} \sim 1.25, \mathrm{I}_{\mathrm{p}} \leq 1.4 \mathrm{MA}, \mathrm{B}_{\mathrm{T}}$ $=0.3-0.6 \mathrm{~T}, \kappa \leq 2.7, \delta \leq 0.8$, and with auxiliary heating of up to $6 \mathrm{MW}$ of High Harmonic Fast Waves, and $7 \mathrm{MW}$ of $100 \mathrm{keV} \mathrm{D}{ }^{0}$ Neutral Beam Injection (NBI). The energy confinement time in plasmas heated by NBI has exceeded $100 \mathrm{~ms}$ and a toroidal beta, $\beta_{\mathrm{T}}=$ $2 \mu_{0}<\mathrm{p}>/ \mathrm{B}_{\mathrm{T} 0}{ }^{2}$, where $\mathrm{B}_{\mathrm{T} 0}$ is the central vacuum toroidal magnetic field, up to $40 \%$ has been achieved. The ability to control the plasma position and shape has been an integral part of the success of NSTX. The rtEFIT - isoflux algorithm for real-time plasma control ${ }^{1}$, originally developed at General Atomics for use on DIII-D, has been modified for control of the plasma equilibrium in NSTX. This control algorithm provides a valuable tool to control a variety of plasma shapes in NSTX. The rtEFIT code provides the shape of the plasma boundary that is used as input to an isoflux control algorithm that generates voltage requests to the power supplies. The plasma boundaries reconstructed in real-time compare well to those reconstructed using the between-shots equilibrium reconstruction from NSTX EFIT. $^{2}$ Examples of the utility of the rtEFIT - isoflux algorithm include: providing plasmas with a well-controlled plasma to antenna separation for HHFW experiments, and experiments with a double null plasma shape wherein a shot-to-shot scan of the separation between the two separatrix flux surfaces at the outboard midplane (drsep) was accomplished in several shots in a well-controlled manner. Recent efforts have reduced the latency in the real-time data flow from the sensors to the power supplies from $\sim 4 \mathrm{~ms}$ to less than $1 \mathrm{~ms}$ and added a pair of voltage loops for use in the vertical control. Together, these improved vertical position control and allowed control of plasmas nearer stability boundaries.

\section{Control System}

The control system on NSTX is based on a Skybolt II 6U VME Multiprocessor system with eight-333 Mhz G4 processors. The system acquires 11 measured coil currents, 65 magnetics signals and 9 loop voltages (for estimating vessel eddy currents) at a $5 \mathrm{kHz}$ rate. The data provides the input to the control algorithms, including coil current feedback, plasma current feedback, simple gap control, vertical position control and rtEFIT - isoflux. The plasma control system $(\mathrm{PCS})^{3}$ determines which of these algorithms is being and this allows different categories, for example: toroidal field current, plasma current $\left(\mathrm{I}_{\mathrm{p}}\right) / \mathrm{ohmic}$ 
transformer current $\left(\mathrm{I}_{\mathrm{OH}}\right)$, and plasma shape. Different phases can be used for each category, for example in the plasma shape category, the algorithm used to control the poloidal field coil curents $\left(\mathrm{I}_{\mathrm{PF}}\right)$ can be switched from a simple one using feedback on $\mathrm{I}_{\mathrm{PF}}$ at start-up, to one using feedback on a simple gap and $\mathrm{I}_{\mathrm{PF}} / \mathrm{I}_{\mathrm{p}}{ }^{4}$ for shaping, to one using rtEFIT isoflux control. The output of the algorithm in each phase is a new voltage request for each coil. The system uses a lookup table to generate the firing angles that are transmitted to the rectifiers via a digital link. Latency in the control system (the time from receiving a change in an input signal to when the system makes a response) should be less than the time response of the powers supplies in order to minimize the impact of the computer latency on the overall control loops. Recent improvements in the software and hardware have reduced the time from a change in input signals until the rectifiers receive a new command from about $4 \mathrm{~ms}$ to about $0.75 \mathrm{~ms}$. This compares favourably to the time for the 12 phase rectifiers to respond to the commands and has allowed routine operation at higher elongation than was possible before this improvement.

\section{3. rtEFIT calculation}

Use of real time equilibrium reconstruction (rtEFIT) in tokamak discharge control, a

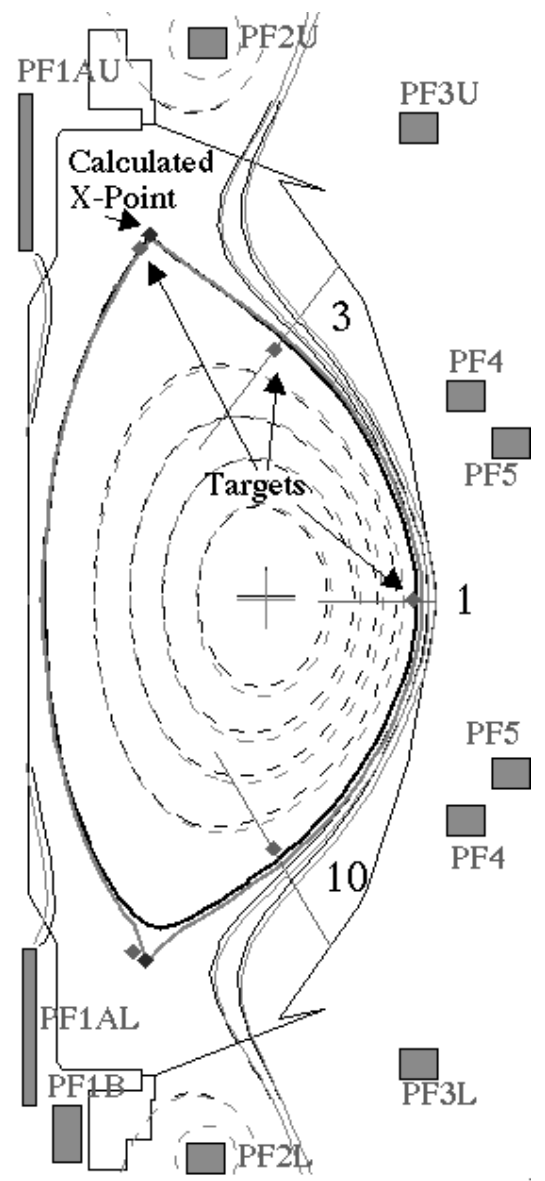

Figure 1. Flux plots from EFIT (gray) and rtEFIT(black) analysis for the same time during a discharge. technique first accomplished on the DIII-D tokamak, is described in Ref. 1. rtEFIT is an approximate solution to the Grad-Shafranov equilibrium relation that fits the diagnostic measurements and provides the spatial distribution of toroidal current and poloidal flux in a time that is sufficient for discharge control. The implementation of this technique on NSTX was facilitated by the experience gained on DIII-D. The fundamental approach is the same. On NSTX, the vacuum vessel is modelled as 30 separate segments in rfEFIT. Nine measured loop voltage signals are used to estimate the currents in 10 of the vacuum vessel segments ${ }^{5}$, which along with the 11 poloidal field coil currents, are treated as known values rather than values to be fit in the calculation. Figure 1 shows the poloidal flux plots from EFIT and from rtEFIT using the same diagnostic set during the flattop of an NSTX discharge. This example is typical of the agreement between the two calculations during the current flattop. The positions of the $\mathrm{X}$-points agree to a few $\mathrm{mm}$ in radius and $.01 \mathrm{~m}$ in height. EFIT finds the outer flux boundary to be slightly larger than does rtEFIT, the difference is approximately $0.01 \mathrm{~m}$ at the outer midplane. The difference is due to the dissimilarity between the computation grid size in rtEFIT (33 by 33) and in EFIT (65 by 65) and the use of a different 
current profile parameterization. When rtEFIT and EFIT are run with exactly the same data, options and computation grid size they produce the same results. These small, but consistent, differences using the smaller grid size in rtEFIT are acceptable for plasma control.

\section{Control algorithms}

During an NSTX discharge, plasma shape is controlled by the poloidal field coil currents in phases that proceed from feedback on coil currents at the start of the shot, to feedback on a simple gap, vertical position feedback and $\mathrm{I}_{\mathrm{PF}} / \mathrm{I}_{\mathrm{p}}$, to feedback on the flux boundary (rtEFIT isoflux control). Use of the first two phases is described in more detail in reference 4. For rtEFIT - isoflux control, a target boundary shape such as one shown in Fig. 1 from an equilibrium reconstruction of an NSTX plasma is used. The use of an existing discharge shape as a target shape to which changes can be made helps to ensure that the desired shape

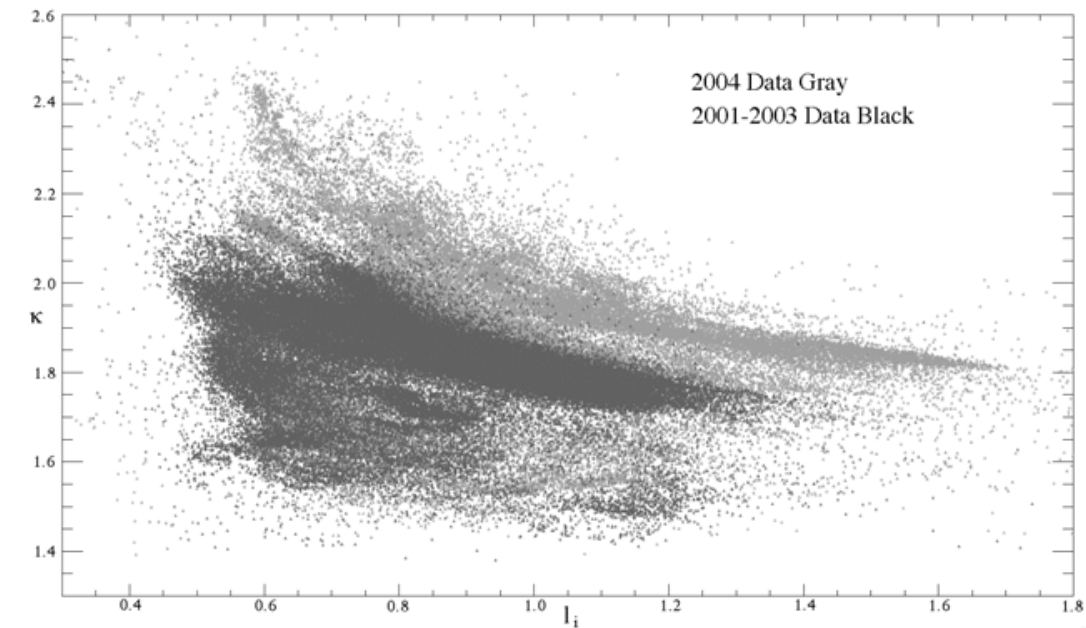

Figure 2. $\kappa$ versus $1_{i}$ for NSTX discharges, data is taken from the current flattop of the discharge. is achievable. In order to describe how isoflux control is accomplished consider the location of the last closed flux surface at the outer midplane. The control point for this location is the intersection of the plasma boundary shape and the line segment number 1 at the outer midplane in Fig. 1. The coil current in PF5 is adjusted to make the flux at the control point equal to the flux at the reference control point with a PID controller. PF3U (PF3L) is used to control the flux at the intersection of the reference boundary and segment 3 (10). PF2U (PF2L) is used to control the height of the upper (lower) X-point that is specified by the operator. The effect of PF1AU and PF1AL on the nearby plasma boundary and on the location of the X-point is dependent upon the plasma height and upon the plasma inductance in a manner that does not lead to a simple control scheme and learning the best way to implement control of these coils is in progress. The PF4 coils have not been used. PF1B has been useful for producing lower single null plasmas and has yet to be used with rtEFIT - isoflux control. In order to accomplish vertical control near the stability limit, it is important to have a signal that is fast and has a derivative term that is less than the noise in the system. We found that the difference in the voltage loop signals between the upper and lower passive plates provided a better signal to noise ratio than either the derivative of the flux error in segments 3 and 10 from rt-EFIT or the derivative of the associated integrated flux loop signals and permitted operation closer to the stability limit. The increased operating space is illustrated in Fig. 3, which shows the limit in plasma elongation ( $\kappa)$ vs $l_{i}$. The increase in $\kappa$ is about half due to 
the reduced latency mentioned earlier and half to the use of the loop voltage difference signal.

\section{Results}

Control of the gap between the plasma and the RF antennas is important in order to maintain adequate coupling between the antennas and the plasma. Figure 3 shows the gap at the outer midplane during the flattop of a series of discharges during an RF heating experiment. The gap was controlled to about $0.01 \mathrm{~m}$ despite large transients and changes in RF power. Each shot shows a transient from $0.06 \mathrm{~m}$ to $0.03 \mathrm{~m}$ due to a mismatch in the outer gap request at the beginning of rt-EFIT - isoflux control, which in turn was due to a mismatch between the
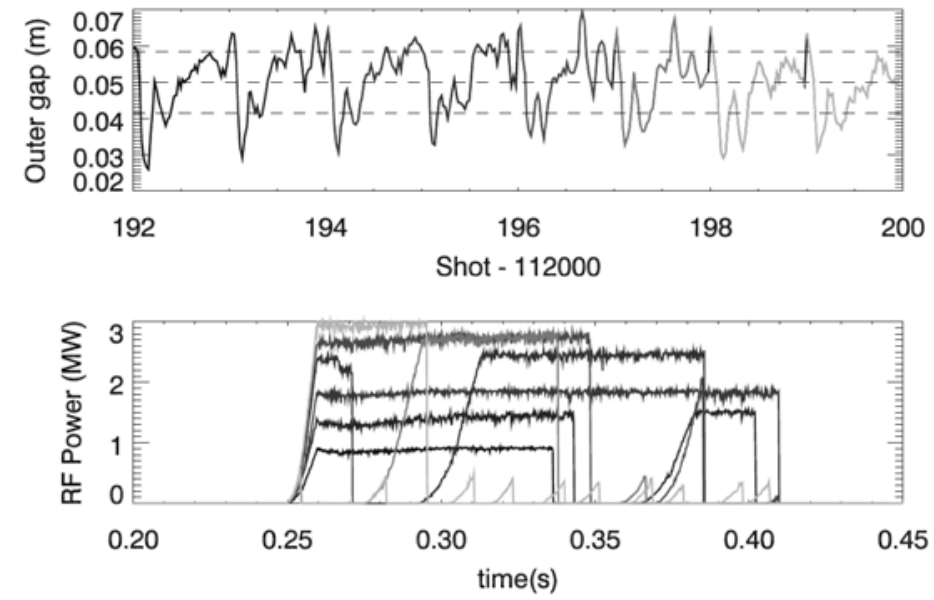

Figure 3. The top shows the outer gap at the midplane concatenated from the current flattops $(0.2-0.45 \mathrm{~s})$ of a series of RF heated discharges. The large variations in RF power from shot-to-shot are overlaid in the lower plot. requested gap in the two phases. Control of the shape of double null plasmas to vary drsep can be useful to determine how the plasma performance depends on shape. rtEFIT-isoflux control of drsep towards a lower single null shape is accomplished by changing the control point number 3 towards the center of the plasma by 4 times the desired midplane separation of the two separatrix flux surfaces (the factor 4 is to accommodate flux expansion off the midplane) while controlling the $\mathrm{X}$-point heights to remain the same.

\section{Summary}

The implementation of the rtEFIT - isoflux algorithm in the digital control system for NSTX has led to improved ability to control the plasma shape. In particular, it has been essential for good gap control for RF experiments, for control of drsep in H-mode studies, and for Xpoint height control and $\kappa$ control in a variety of experiments.

* Work supported at PPPL under U.S. DOE Contract DE-AC02-76CH03073

\section{References}

${ }^{1}$ J. R. Ferron et al., Nucl. Fusion, 38, p. 1055 (1998).

${ }^{2}$ L.L. Lao et al., Nucl. Fusion, 25, p. 1611 (1985) and S. A. Sabbagh et al., Nucl. Fusion, 41, p. 1601 (2002).

${ }^{3}$ J. R. Ferron, et al., Proc. Of the 16th IEEE/NPSS Symposium on Fusion Engineering, Champaign, IL Vol. 2, p. 870 (1996).

${ }^{4}$ D. Gates, et al., IEEE Trans. Nucl. Sci., 47, p. 222 (2000).

${ }^{5}$ D. Gates, et al., submitted to RSI (2004). 


\section{External Distribution}

Plasma Research Laboratory, Australian National University, Australia

Professor I.R. Jones, Flinders University, Australia

Professor João Canalle, Instituto de Fisica DEQ/IF - UERJ, Brazil

Mr. Gerson O. Ludwig, Instituto Nacional de Pesquisas, Brazil

Dr. P.H. Sakanaka, Instituto Fisica, Brazil

The Librarian, Culham Laboratory, England

Mrs. S.A. Hutchinson, JET Library, England

Professor M.N. Bussac, Ecole Polytechnique, France

Librarian, Max-Planck-Institut für Plasmaphysik, Germany

Jolan Moldvai, Reports Library, Hungarian Academy of Sciences, Central Research Institute for Physics, Hungary

Dr. P. Kaw, Institute for Plasma Research, India

Ms. P.J. Pathak, Librarian, Institute for Plasma Research, India

Ms. Clelia De Palo, Associazione EURATOM-ENEA, Italy

Dr. G. Grosso, Instituto di Fisica del Plasma, Italy

Librarian, Naka Fusion Research Establishment, JAERI, Japan

Library, Laboratory for Complex Energy Processes, Institute for Advanced Study, Kyoto University, Japan

Research Information Center, National Institute for Fusion Science, Japan

Dr. O. Mitarai, Kyushu Tokai University, Japan

Dr. Jiangang Li, Institute of Plasma Physics, Chinese Academy of Sciences, People's Republic of China

Professor Yuping Huo, School of Physical Science and Technology, People's Republic of China

Library, Academia Sinica, Institute of Plasma Physics, People's Republic of China

Librarian, Institute of Physics, Chinese Academy of Sciences, People's Republic of China

Dr. S. Mirnov, TRINITI, Troitsk, Russian Federation, Russia

Dr. V.S. Strelkov, Kurchatov Institute, Russian Federation, Russia

Professor Peter Lukac, Katedra Fyziky Plazmy MFF UK, Mlynska dolina F-2, Komenskeho Univerzita, SK-842 15 Bratislava, Slovakia

Dr. G.S. Lee, Korea Basic Science Institute, South Korea

Institute for Plasma Research, University of Maryland, USA

Librarian, Fusion Energy Division, Oak Ridge National Laboratory, USA

Librarian, Institute of Fusion Studies, University of Texas, USA

Librarian, Magnetic Fusion Program, Lawrence Livermore National Laboratory, USA

Library, General Atomics, USA

Plasma Physics Group, Fusion Energy Research Program, University of California at San Diego, USA

Plasma Physics Library, Columbia University, USA

Alkesh Punjabi, Center for Fusion Research and Training, Hampton University, USA

Dr. W.M. Stacey, Fusion Research Center, Georgia Institute of Technology, USA

Dr. John Willis, U.S. Department of Energy, Office of Fusion Energy Sciences, USA

Mr. Paul H. Wright, Indianapolis, Indiana, USA 
The Princeton Plasma Physics Laboratory is operated by Princeton University under contract with the U.S. Department of Energy.

\author{
Information Services \\ Princeton Plasma Physics Laboratory \\ P.O. Box 451 \\ Princeton, NJ 08543
}

Phone: 609-243-2750

Fax: 609-243-2751

e-mail: pppl_info@pppl.gov

Internet Address: http://www.pppl.gov 